\title{
Endogenous Truncated TrkB.T1 Receptor Regulates Neuronal Complexity and TrkB Kinase Receptor Function In Vivo
}

\author{
Laura Carim-Todd, ${ }^{1 \star}$ Kevin G. Bath, ${ }^{2 *}$ Gianluca Fulgenzi, ${ }^{1,3}$ Sudhirkumar Yanpallewar, ${ }^{1}$ Deqiang Jing, ${ }^{2}$ \\ Colleen A. Barrick, ${ }^{1}$ Jodi Becker, ${ }^{1}$ Hannah Buckley, ${ }^{1}$ Susan G. Dorsey, ${ }^{1,4}$ Francis S. Lee, ${ }^{2}$ and Lino Tessarollo ${ }^{1}$ \\ ${ }^{1}$ Neural Development Group, Mouse Cancer Genetics Program, Center for Cancer Research, National Cancer Institute, Frederick, Maryland 21702, \\ ${ }^{2}$ Department of Psychiatry, Weill Cornell Medical College of Cornell University, New York, New York 10065, ${ }^{3}$ Department of Molecular Pathology, \\ University of Marche, 60020 Ancona, Italy, and ${ }^{4}$ Organizational Systems and Adult Health, University of Maryland School of Nursing, Baltimore, Maryland 21201
}

Pathological or in vitro overexpression of the truncated TrkB (TrkB.T1) receptor inhibits signaling through the full-length TrkB (TrkB.FL) tyrosine kinase receptor. However, to date, the role of endogenous TrkB.T1 is still unknown. By studying mice lacking the truncated TrkB.T1 isoform but retaining normal spatiotemporal expression of TrkB.FL, we have analyzed TrkB.T1-specific physiological functions and its effect on endogenous TrkB kinase signaling in vivo. We found that TrkB.T1-deficient mice develop normally but show increased anxiety in association with morphological abnormalities in the length and complexity of neurites of neurons in the basolateral amygdala. However, no behavioral abnormalities were detected in hippocampal-dependent memory tasks, which correlated with lack of any obvious hippocampal morphological deficits or alterations in basal synaptic transmission and long-term potentiation. In vivo reduction of TrkB signaling by removal of one BDNF allele could be partially rescued by TrkB.T1 deletion, which was revealed by an amelioration of the enhanced aggression and weight gain associated with BDNF haploinsufficiency. Our results suggest that, at the physiological level, TrkB.T1 receptors are important regulators of TrkB.FL signaling in vivo. Moreover, TrkB.T1 selectively affects dendrite complexity of certain neuronal populations.

Key words: TrkB.T1; BDNF; mouse; anxiety; neurites; amygdala

\section{Introduction}

The neurotrophins NGF, BDNF, NT-3, and NT-4 are key regulators of the development and function of the mammalian nervous system (Bibel and Barde, 2000; Huang and Reichardt, 2001; Chao et al., 2006). Some of their prominent roles include regulation of cell survival and cell death, modulation of synaptic transmission, neurite outgrowth, and branching (Snider, 1994; Cellerino and Maffei, 1996; Tessarollo, 1998; McAllister et al., 1999; Hempstead, 2002; Lu et al., 2005). Neurotrophin functions are mediated by three type of receptors: the Trk tyrosine kinase receptors; p75, a member of the tumor necrosis factor receptor superfamily; and sortilin, a Vps10p domain-containing transmembrane protein (Bothwell, 1995; Chao and Hempstead, 1995; Friedman and Greene, 1999; Kaplan and Miller, 2000; Nykjaer et al., 2004). The existence of several Trk receptor isoforms, such as the full-length Trk tyrosine kinase receptors (TrkB.FL) and the

Received 0ct. 20, 2008; revised Dec. 5, 2008; accepted Dec. 10, 2008.

This work was supported by the Intramural Research Program of the National Institutes of Health (NIH), National Cancer Institute, (enter for Cancer Research, and NIH Grants MH060478 (K.G.B.) and NS052819 (F.S.L.).

*L.C.-T. and K.G.B. contributed equally to this work.

Correspondence should be addressed to Dr. Lino Tessarollo, Neural Development Group, Mouse Cancer Genetic Program, National Cancer Institute-Frederick, 7th Street, Building 560, Room 32-31D, P.0. Box B, Frederick, MD 21702. E-mail: tessaro@@mail.nih.gov.

D01:10.1523/JNEUROSCI.5060-08.2009

Copyright $\odot 2009$ Society for Neuroscience $\quad$ 0270-6474/09/290678-08\$15.00/0 truncated isoforms (TrkB.T1 and TrkC.T1), which lack intrinsic tyrosine kinase activity, suggests the presence of additional mechanisms to diversify neurotrophin-induced signaling (Klein et al., 1990; Middlemas et al., 1991; Tsoulfas et al., 1993; Valenzuela et al., 1993; Garner and Large, 1994). It has been reported that both truncated TrkB.T1 and TrkC.T1 are capable of signaling independently. However, the physiological significance of these truncated Trk receptor activated signaling pathways is still unknown (Baxter et al., 1997; Rose et al., 2003; Ohira et al., 2005; Esteban et al., 2006). Moreover, although a number of studies using overexpression of these receptors has suggested that both truncated TrkB and TrkC can inhibit full-length tyrosine kinase signaling through a dominant-negative mechanism, the relevance of this mechanism in vivo by the endogenous truncated Trk receptor is still unknown (Biffo et al., 1995; Eide et al., 1996; Palko et al., 1999; Dorsey et al., 2006). In addition, it is also unknown whether specific functions, such as control of dendritic morphology, which are affected by overexpression of truncated TrkB receptors, are regulated by this receptor isoform at the physiological level (Yacoubian and Lo, 2000).

TrkB.T1 is considered the prototype of truncated Trk receptors. It is dynamically upregulated during fetal development and becomes the predominant Trk receptor isoform in the adult animal (Allendoerfer et al., 1994; Escandón et al., 1994; Fryer et al., 1996). Yet, to date, little is known about its physiological function 
in vivo. To address this issue, we have taken advantage of a mouse model that specifically lacks the TrkB.T1 receptor isoform but retains normal spatiotemporal levels of the full-length kinase active TrkB (Dorsey et al., 2006). Although TrkB.T1-deficient mice do not show any overt phenotype, we found that they are more anxious than their control littermates and have morphological changes in the length and complexity of neurites of the basolateral amygdala neurons. Moreover, although loss of TrkB.T1 overall does not affect normal brain development or function, we found that its reduction can improve deficiencies associated with BDNF haploinsufficiency in vivo.

\section{Materials and Methods \\ Animals}

TrkB.T1-deficient mice were generated as described previously and backcrossed 10-12 generations to C57BL/6 mice to provide a sufficiently homogeneous genetic background for testing (Dorsey et al., 2006). We used BDNF heterozygous mice backcrossed on a pure C57BL/6 background (Lyons et al., 1999) to obtain double mutant lines BDNF; TrkB.T1 to test for rescue of the BDNF haploinsufficiency phenotype. All mice were housed two to five per cage, unless otherwise stated, in a temperature- and humidity-controlled vivarium with water and food available ad libitum and maintained on a $12 \mathrm{~h}$ light/dark cycle. All animals were treated in compliance with the National Institutes of Health Guide for Care and Use of Laboratory Animals and approved by institutional Animal Care and Use Committees.

\section{Behavioral analysis}

To reduce experimental variability, male age-matched littermate pairs resulting from heterozygous crossings were used for all experiments. All behavioral measurements were performed by raters blind to genotype.

Weight analysis. Male mice of the indicated genotype were grouped housed and fed a standard chow diet containing 9\% crude fat (PMI Nutrition). Weight was monitored monthly up to 7 months of age.

Resident-intruder assay (Lyons et al., 1999). For isolation-induced aggression, male resident test mice were single housed for at least 4 weeks. Cages were changed once per week but not during the week preceding testing. Aggressive behaviors in 3.5-month-old test mice were monitored during 5 min exposures to wild-type (WT) C57BL/6 male intruder mice that had been group housed (five per cage) and carefully matched with resident mice for body weight. Four test sessions were conducted (one trial per day). The latency to first biting attack and the total number of biting attacks were recorded from videotapes of each test session. For mice that failed to attack, the latency was scored as $5 \mathrm{~min}$.

Open-field test. The open-field apparatus consisted of a white Plexiglas arena $(40 \times 40 \times 49 \mathrm{~cm})$ with a white floor divided into 12 equal quadrants. The arena was set up in a dim room under a digital camera connected to a video recorder and a computer under the control of the EthoVision tracking system (Noldus). A single mouse was placed into the center of the open-field arena, and its behavior was recorded over a 10 min session. Anxiety level was measured by the relative amount of exploration devoted to the center quadrants relative to those located adjacent to the walls of the arena. This was quantified by two indices: (1) percentage of time spent in the center quadrants and (2) percentage of entries into the center quadrants. An entry into a given quadrant was only registered if the center mass of the mouse crossed into the quadrant.

Elevated-plus maze. The elevated-plus maze was constructed of white Plexiglas and raised $70 \mathrm{~cm}$ above the floor. The apparatus consisted of two opposite enclosed arms with 14-cm-high opaque walls and two opposite open arms of the same size $(30 \times 5 \mathrm{~cm})$. The arena was set up in a dim room under a digital camera, connected to a video recorder and a computer under the control of the EthoVision tracking system. A single testing session lasting $10 \mathrm{~min}$ was performed in a dark room. To begin a trial, the test animal was placed in the center of the plus maze facing an open arm, and its behavior was tracked for $10 \mathrm{~min}$. The maze was cleaned with a $50 \%$ ethanol solution and dried after each trial to eliminate possible odor cues left by previous subjects. The number of entries into both the open and enclosed arms (an entry was scored when the center mass of the animal crossed into an arm), the time spent in those two areas, and the frequency of total crosses were recorded. Anxiety levels were measured by the relative amount of exploration devoted to the open arms relative to that to the enclosed arms. This was quantified by two indices: (1) percentage of time spent in the open arms and (2) percentage of entries into the open arms.

Fear conditioning. The conditioning apparatus consisted of a mouse shock chamber (Coulbourn Instruments) set up in a sound-attenuated box and scented with peppermint odor ( $0.1 \%$ peppermint). On day 1 , the conditioning day, after a 2 min acclimation period to the conditioning chamber, mice received three conditioning trials consisting of a $30 \mathrm{~s}$ presentation of a $5 \mathrm{kHz}, 70-\mathrm{dB}$ tone [conditioning stimulus (CS)] that coterminated with a $0.7 \mathrm{~mA}$ foot shock delivered through the grid floor during the last $1.0 \mathrm{~s}$ of the tone. Each conditioning trial was separated by a $30 \mathrm{~s}$ intertrial interval (ITI). After conditioning, mice were returned to their home cages. Mice were videotaped during CS presentations for subsequent quantification of behavior. Time spent "freezing" before and during the presentation of the CS tone was measured during the CS presentation as well as during a $30 \mathrm{~s}$ baseline period before the first tone trial. This latter measure served as an assay for unconditioned effects of the CS on general activity levels. Memory for the context and the tone was evaluated on days 2 and 3 respectively ( $\sim 24$ and $48 \mathrm{~h}$ after conditioning). For the context test, mice were placed in the conditioning chamber and allowed to explore for $2 \mathrm{~min}$, after which freezing to the context was assessed for the remaining $4.5 \mathrm{~min}$. For the tone test, mice were placed in a novel chamber (circular in shape, with green walls, and scented with lemon odor). Mice were allowed to acclimate to the chamber for $2 \mathrm{~min}$ and were then presented with the CS (tone) on three consecutive trials $(30 \mathrm{~s}, 5 \mathrm{kHz}, 70 \mathrm{~dB}$; ITI of $40 \mathrm{~s}$ ). Freezing was evaluated during the $2 \mathrm{~min}$ acclimation period, during each presentation of the tone CS, and during the $40 \mathrm{~s}$ intertrial interval. After memory tests, animals were returned to their home cage and colony. Memory for either the context or tone CS was quantified by the percentage of time engaged in a fear-related behavior (freezing) during context testing or CS presentation.

\section{Histology and morphological analyses}

Rapid Golgi impregnation. Golgi impregnation of all brains was conducted using FD Rapid GolgiStain Kit (FD Neuro Technologies). GolgiCox $(\mathrm{G}-\mathrm{C})$ solution (mixture of A and B solutions from kit) was mixed a minimum of $12 \mathrm{~h}$ before use and stored in a dark place at room temperature. Care was taken during all steps to ensure that solutions did not come in contact with metal surfaces. After extraction from the skull, the brains were immersed in $\mathrm{G}-\mathrm{C}$ solution in a glass bottle for $14 \mathrm{~d}$ at room temperature in a dark place (the G-C mixture was changed after the initial $12 \mathrm{~h}$ of impregnation). After the $14 \mathrm{~d}$ of incubation in $\mathrm{G}-\mathrm{C}$ solution, the brains were transferred to solution $\mathrm{C}(10 \mathrm{ml} / \mathrm{brain})$ and incubated for a minimum of $3 \mathrm{~d}$ at $4^{\circ} \mathrm{C}$, again with the solutions having been changed after the initial $12 \mathrm{~h}$. Brains were then embedded in a $3 \%$ agarose solution, blocked, and cut at room temperature on a vibratome $(150 \mu \mathrm{m}$ sections). Serial sections were immediately mounted onto $0.3 \%$ gelatincoated slides. Once on the slides, and before complete drying of the tissue, the sections were brushed with solution $\mathrm{C}$ and allowed to air dry for $48 \mathrm{~h}$. Slides were then immersed in $\mathrm{dd}_{2} 0$ three times for 5 min with gentle shaking, transferred into a solution of D plus $\mathrm{E}$ (from the Golgi kit) ( $25 \mathrm{ml}$ of D, $25 \mathrm{ml}$ of $\mathrm{E}$, and $150 \mathrm{ml}$ of $\mathrm{dH}_{2} 0$ ) for $5-10 \mathrm{~min}$ at $4^{\circ} \mathrm{C}$, and again rinsed three times $\left(5 \mathrm{~min}\right.$ ) in $\mathrm{ddH}_{2} \mathrm{O}$. Slides were then dehydrated through graded ethanols, cleared with Histoclear (three times for $5 \mathrm{~min}$ ), and coverslipped with DPX mounting medium.

Golgi tracing: dentate gyrus and basolateral amygdala neuron inclusion criteria and analyses. Slides containing the Golgi-impregnated brain sections were coded before quantitative analysis to blind the experimenter to genotype; the code was not broken until the analysis was complete. Hippocampal dentate gyrus (DG) neurons were examined in the dorsal hippocampus. With respect to the basolateral amygdala, pyramidal-like neurons were analyzed using inclusion criteria established in previously published morphological studies (Vyas et al., 2002, 2004; Mitra et al., 2005). To be selected for analysis of dendritic arborization, Golgiimpregnated DG granule cells needed to satisfy the following criteria: (1) 
isolated cell body with a clear relationship of the primary dendrite to the soma; (2) presence of untruncated dendrites and dark impregnation along the extent of all of the dendrites; and (3) relative isolation from neighboring impregnated cells that could interfere with the analysis. For each brain, 50 neurons from each region were selected. Cells were traced under $40 \times$ magnification using Neurolucida software (MicroBrightField). The morphological traits of cells (Sholl analysis and fractal dimension analysis) were analyzed using Neuroexplorer (MicroBrightField). Data were processed and analyzed statistically using Prism 4.0 (GraphPad Software).

\section{Electrophysiology}

After isofluorane anesthesia, decapitation, and removal of the brain, transverse hippocampal slices (350 $\mu \mathrm{m}$ thick) were obtained with a vibroslicer (Leica) in ice-cold artificial CSF (ACSF) containing the following (in mM): $125 \mathrm{NaCl}, 1.25 \mathrm{KCl}, 1 \mathrm{CaCl}_{2}, 1.5 \mathrm{MgCl}_{2}, 1.25 \mathrm{KH}_{2} \mathrm{PO}_{4}, 25$ $\mathrm{NaHCO}_{3}$, and 16 glucose, $\mathrm{pH}$ 7.4. Ten micromolar kynurenic acid was added to the sectioning solution to reduce excitotoxicity. Slices were incubated for $1 \mathrm{~h}$ at $32^{\circ} \mathrm{C}$ in a surface chamber filled with ACSF in which $\mathrm{CaCl}_{2}$ was raised to $2.5 \mathrm{~mm}$, and a gas mixture $\left(95 \% \mathrm{O}_{2}, 5 \% \mathrm{CO}_{2}\right)$ was continuously bubbled. After the first hour, temperature was reduced to $28^{\circ} \mathrm{C}$, and slices were kept in the same chamber until the transfer to the recording chamber. Slices were used within $10 \mathrm{~h}$ after sectioning. Extracellular field recording was performed in a submerged recording chamber. Slices were perfused with ACSF at $28^{\circ} \mathrm{C}$ at the rate of $2 \mathrm{ml} / \mathrm{min}$. Two Teflon-coated concentric platinum-iridium electrodes were placed in the stratum radiatum in the CA1 area of the dorsal hippocampus, $\sim 300-$ $400 \mu \mathrm{m}$ apart. Borosilicate glass recording electrodes were pulled (Sutter Instruments P90), ACSF filled to get 4-7 M $\Omega$ resistance, and placed in the apical dendritic region of CA1 pyramidal neurons evenly spaced with respect to the stimulating electrode. Field EPSP (fEPSP) was obtained by alternate stimulation of the two electrodes by activation of the Shaffer collaterals. One of the electrodes was used as a control electrode, whereas the other was used to deliver the conditioning protocol. An input-output curve was obtained independently for each of the stimulating electrodes by gradually increasing the stimulus intensity until fEPSP reached a plateau, after which the stimulus was reduced to obtain a fEPSP that was $50 \%$ of the maximum. Baseline recording was obtained by stimulating the slice every $20 \mathrm{~s}$ for at least $45 \mathrm{~min}$. Once the baseline was stabilized to obtain long-term potentiation (LTP), two $250 \mathrm{~ms}, 100 \mathrm{~Hz}$ trains every $20 \mathrm{~s}$ were delivered to the conditioning electrode. The weaker conditioning protocol compared with the commonly used one of two $1 \mathrm{~s}, 100 \mathrm{~Hz}$ was used to avoid saturation of the LTP and allow to record an eventual increase of the response in the mutant mouse. Baseline recording was then resumed and followed for $1 \mathrm{~h}$. Field potential was recorded (Multiclamp 700b; Molecular Devices), digitized (10 kHz Digidata 1324), lowpass filtered ( $3 \mathrm{kHz}$, eight-pole Bessel), and stored (Clampex 9.2; Molecular Devices). Signals were analyzed offline (Clampfit 9.2; Molecular Devices ), and the size of the fEPSP was evaluated by measuring the initial slope of the signal expressed as percentage of the variation from the baseline value (average of $5 \mathrm{~min}$ before the conditioning protocol). Results were further analyzed with Igor Pro 6.01 (WaveMetrics). All data are reported as means \pm SEs.

\section{Statistics for behavior studies and morphological analyses}

When two means were compared, statistical significance of their difference was calculated using nonpaired Student's $t$ test. In multiple comparisons, data were analyzed by one-way ANOVA with a Bonferroni's post hoc test to determine statistical significance between genotypes. Oneway ANOVA followed by Tukey's multiple comparison test was used for statistical analysis of weight and aggressive behavior.

\section{Results}

We have reported previously that TrkB.T1-deficient animals are viable, fertile, and do not display any overt phenotype (Dorsey et al., 2006). Targeting of the TrkB.T1 coding exon does not cause compensatory upregulation of other truncated TrkB receptor isoform (i.e., TrkB.T2) in neither neurons nor glia (Dorsey et al., 2006) (data not shown). In addition, we have not detected any
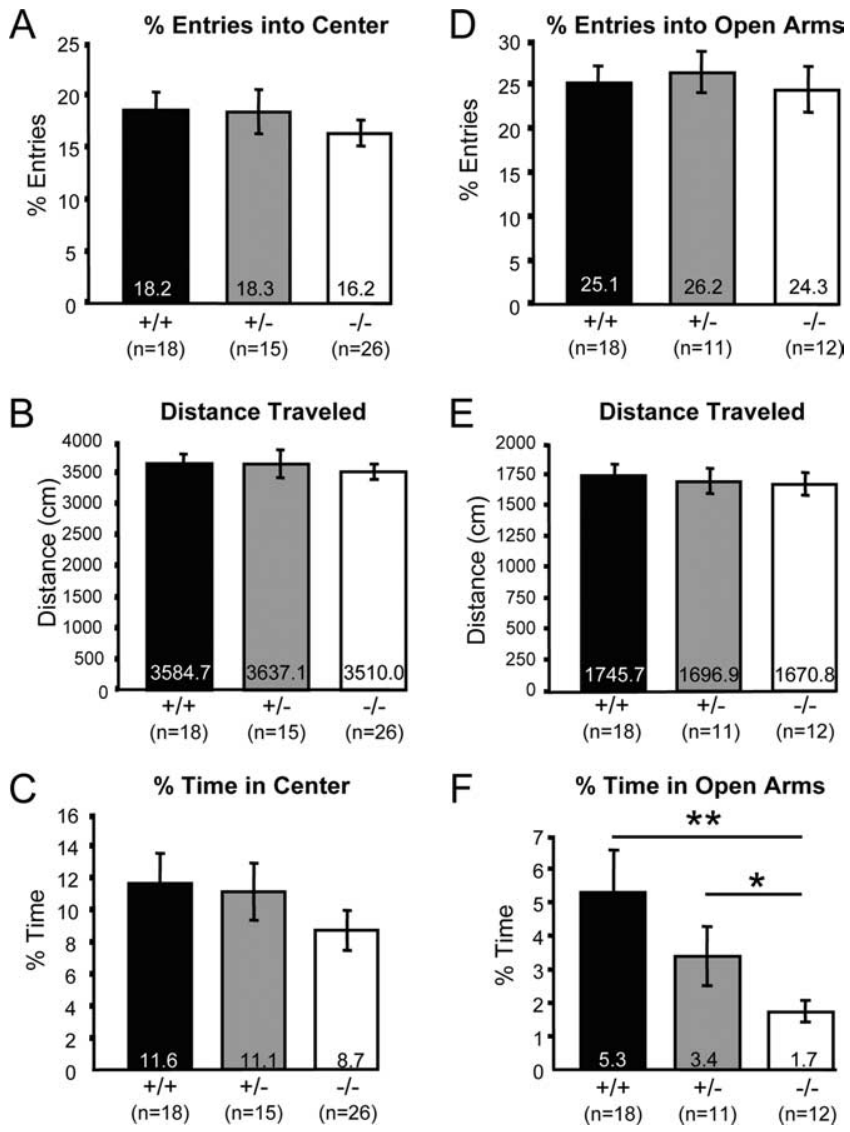

Figure 1. TrkB.T1-deficient animals have increased anxiety-like behavior. The behavior of $+/+,+/-$, and $-I-$ TrkB.T1 mice was analyzed using the open-field $(\boldsymbol{A}-\boldsymbol{C})$ and the elevated-plus maze $(\boldsymbol{D}-\boldsymbol{F})$ tests. Mouse performances were video recorded and analyzed blindly. For the open-field test, the number of mouse entries into the center $(\boldsymbol{A})$, distance traveled $(\boldsymbol{B})$, and time spent in the center of the arena $(\boldsymbol{C})$ were determined. Anxiety level was measured by the relative amount of exploration devoted to the central quadrants relative to those located adjacent to the walls of the arena. For the elevated-plus maze test, the number of entries into the open arms $(\boldsymbol{D})$, distance traveled $(\boldsymbol{E})$, and time spent in the open arms $(\boldsymbol{F})$ were scored. Anxiety was measured by the relative amount of exploration invested in the open arms relative to that of the enclosed arms. For each test, mouse behavior was followed for $10 \mathrm{~min}$. ${ }^{*} p<0.05$; ${ }^{* *} p<0.01$.

change in the level of expression of either full-length or truncated TrkC receptors (data not shown), suggesting that possible abnormalities in this mouse model are caused by the specific deletion of TrkB.T1.

Because BDNF/TrkB-activated signaling pathways are critical for the control of a variety of developmental processes, including nervous system functions, we characterized this mutant to assess the role of TrkB.T1 in TrkB.FL signaling and in long-term organism homeostasis. Aging of mutant mice for over 2 years revealed that they have a normal lifespan compared with WT littermates (data not shown). Furthermore, they do not show changes in tumor development, suggesting that TrkB.T1 does not control cell proliferation per se (data not shown). We then investigated whether endogenous TrkB.T1 causes specific developmental deficits or whether it exerts inhibitory roles on TrkB.FL at the physiological level. These two aspects of the characterization of the TrkB.T1 mouse model are important because of the suggested intrinsic signaling role for TrkB.T1 (Baxter et al., 1997; Rose et al., 2003; Ohira et al., 2005) and because TrkB.T1 dominant-negative in vivo functions on TrkB.FL signaling have been demonstrated only in pathological or transgenic overexpression conditions 


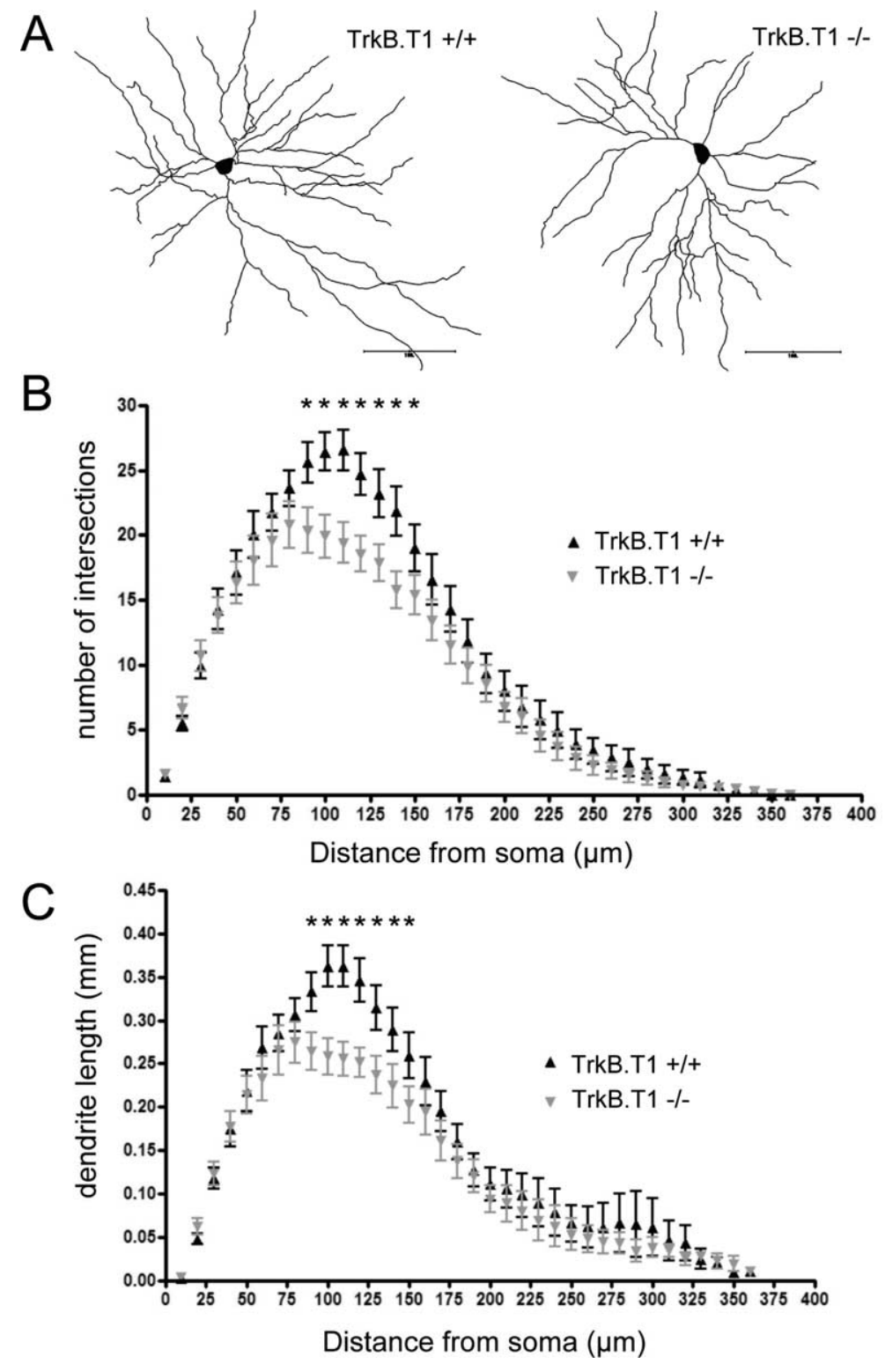

Figure 2. $T r k B \cdot T 1^{-1-}$ mice have decreased neuronal complexity in the amygdala. Morphological analysis of basolateral amygdala neurons visualized by the rapid Golgi impregnation method. $\boldsymbol{A}$, Neurolucida representation of a typical stained basolateral amygdala neuron from $T r k B . T 1^{-1-}$ (right) and wild-type control (left) mouse brain sections. Sholl analysis of the number of dendrite intersections $(\boldsymbol{B})$ and length of dendrites of amygdala neurons ( $\boldsymbol{C}$. Postnatal day 60 mice and 25 neurons per mouse were used in the analysis. All results are presented as means \pm SEM determined from analyzing six mice per genotype. ${ }^{*} p<0.01$

(Saarelainen et al., 2000a,b; Dorsey et al., 2006). No direct in vivo role for endogenous TrkB.T1 has been demonstrated to date.

\section{TrkB.T1-deficient mice have increased anxiety and} basolateral amygdala dendrite abnormalities

To address the role of TrkB.T1 in neuronal functions, we performed behavioral analyses on TrkB.T1-deficient mice to assess phenotypes that are affected by BDNF/TrkB signaling such as anxiety, learning and memory, and aggression.

Mice were first subjected to the open-field test to investigate whether there was any difference in basal locomotor activity and the time spent in the center versus the edges of the arena. No significant differences were observed in either parameter analyzed, suggesting that TrkB.T1 mutant mice do not have any major impairment in this paradigm (Fig. $1 A-C$ ).
However, we did notice a trend toward mutant mice spending less time in the center of the arena and making fewer entries into the middle, suggesting that TrkB.T1 deficiency may cause increased anxiety (Fig. $1 A, C)$. We then used the elevated-plus maze, an assay that is more sensitive in detecting anxiety-related phenotypes. Although TrkB.T1 ${ }^{-1-}$ mice entered the open arms as many times as their control littermates, they did spend significantly less time in the open arms, a behavior that is consistent with an increased anxiety phenotype (Fig. $1 D-F$ ). TrkB.T1 is highly expressed in the hippocampus, a region associated with learning and memory functions. Moreover, impairments in BDNF signaling have been shown to affect hippocampaldependent memory functions in both humans and rodents (Egan et al., 2003; Hariri et al., 2003; Chen et al., 2006). Thus, we subjected TrkB.T1 mutant mice to a contextual fear-conditioning test, a hippocampusand amygdala-dependent memory task. We found no differences in the percentage of freezing to context $(52.8 \pm 7.9 \% \mathrm{WT}$, $\left.n=10 ; 46.2 \pm 6.3 \% \operatorname{TrkB} . T 1^{-/-}, n=9\right)$ and to cue $(68.9 \pm 3.5 \% \mathrm{WT}, n=10$; $73.7 \pm 1.6 \% \operatorname{TrkB} . T 1^{-/-}, n=9$ ) between WT or TrkB.T1 mutant animals, suggesting that there are no impairments in either associative learning or hippocampaldependent encoding of environmental cues. The specific alteration in anxiety levels and the lack of deficits in memory functions prompted us to investigate whether TrkB.T1 deletion caused any anatomical deficit in the amygdala, a brain region known to control anxiety in mammals. We used Golgi staining to visualize individual basolateral amygdala neurons (Fig. 2A). At 8 weeks of age, there was no difference in cell soma area between TrkB.T1 mutant mice and their WT controls (data not shown). Next, we analyzed dendritic complexity in these same neurons. Sholl analysis revealed a decrease in dendritic arbor complexity at $90 \mu \mathrm{m}$ and greater distances from the soma in TrkB.T1 mutant neurons (Fig. $2 B$ ). In addition, we also observed a decrease in dendritic length (Fig. $2 C$ ). These observations, in correlation with the elevated-plus maze results, suggest that the reduced morphological complexity of $\operatorname{Tr} k B . T 1^{-1-}$ neurons in the basolateral amygdala can be in part responsible for the increased anxiety of TrkB.T1 mutant mice. When the morphology of neurons in the dentate gyrus of the hippocampus was examined, no significant differences between genotypes were detected in cell soma size (data not shown), dendrite length (data not shown), or dendritic complexity by Sholl analysis (Fig. 3). There was a trend toward decreased dentate gyrus dendritic arbor complexity at 150 $\mu \mathrm{m}$ and greater distances in TrkB.T1 mutant mice, but it was not statistically significant (Fig. 3B). This result correlates with the behavioral analysis, because TrkB.T1 mutant mice showed no deficits 

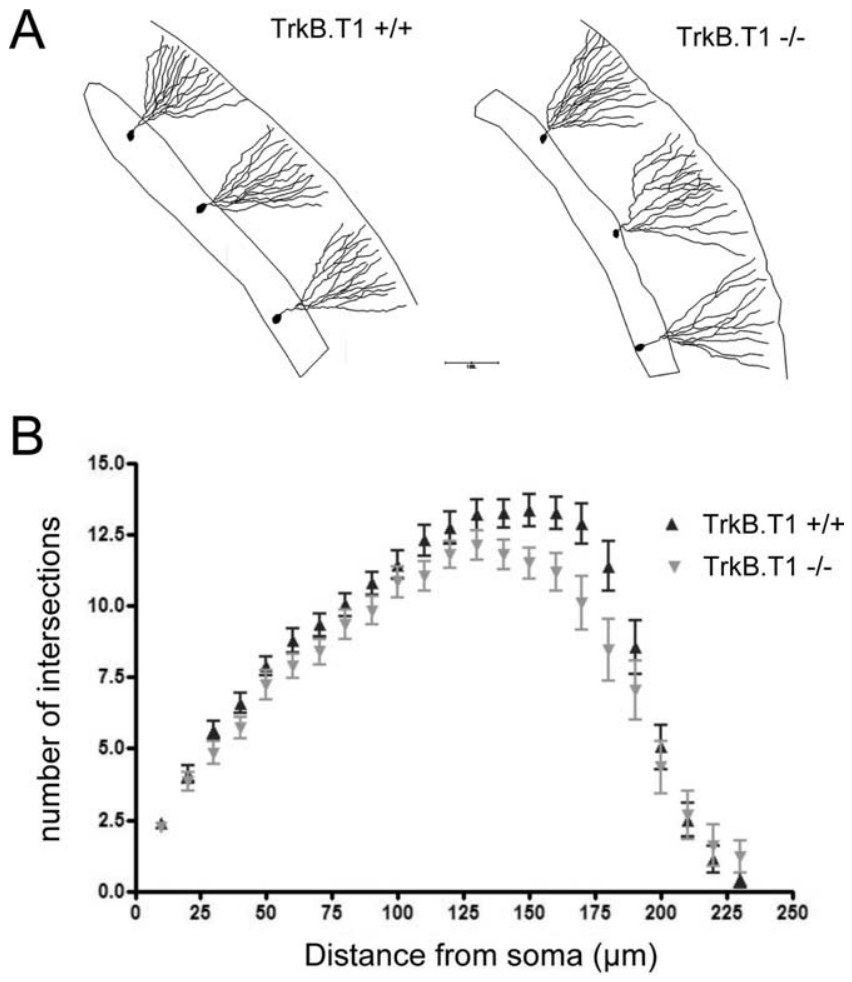

Figure 3. Loss of TrkB.T1 does not affect hippocampus neurite morphology. $\boldsymbol{A}$, Representative examples of Golgi-stained dentate gyrus neurons from postnatal day 60 wild-type $(+/+$; left) and TrkB.T1-deficient (-/-;right) mice. Sholl analyses of the number of intersections ( $\boldsymbol{B})$ in hippocampal dentate gyrus neurons. All results are presented as means \pm SEM determined by analysis of six mice per genotype and 25 neurons per mouse. ${ }^{*} p<0.01$.

in learning and memory performance in the hippocampaldependent contextual fear-conditioning paradigm.

\section{TrkB.T1 does not affect hippocampal basal synaptic transmission and LTP}

To further characterize whether the TrkB.T1 deletion may result in deficits that are not immediately apparent by behavioral or morphological characterization, we decided to analyze the basal synaptic transmission and LTP in TrkB.T1-deficient mice. We reasoned that a small deficit in LTP may not cause a short-term anatomical or behavioral abnormality but could have long-term effects on the animal's memory functions. We found that LTP in the CA1 area of the dorsal hippocampus at $1 \mathrm{~h}$ after the conditioning in WT animal $(141.75 \pm 6.25 \%, n=16)$ was similar to that found in TrkB.T1-deficient mice (128.14 $\pm 9.84 \%, n=10)$, suggesting that loss of TrkB.T1 does not affect this aspect of hippocampal synaptic plasticity (Fig. 4). Furthermore, the basal synaptic transmission appeared to be normal, as assessed by the input-output curves (stimulus intensity vs fEPSP slope) from the Schaffer collateral-CA1 region. Again, these results are consistent with the normal learning and memory function observed in the behavioral studies and the lack of abnormalities in the morphology of DG neurons in TrkB.T1 mutant animals.

TrkB.T1 deletion partially rescues BDNF haploinsufficiency We and others have reported previously that BDNF heterozygous mice exhibit enhanced aggression as well as increased food consumption that leads to obesity (Lyons et al., 1999; Kernie et al., 2000; Rios et al., 2001; Coppola and Tessarollo, 2004). Because the severity of the phenotypes caused by BDNF/TrkB deficiency parallels the level of loss of this signaling pathway (Lyons et al., 1999; Rios et al., 2001; Xu et al., 2003), we reasoned that even minimal increases in BDNF/TrkB signaling could have an impact on the degree of obesity and aggression caused by deletion of a single BDNF allele. Indeed, introducing the TrkB.T1 mutation into a $\mathrm{BDNF}^{+/-}$background partially rescues both phenotypes, consistent with an inhibitory role for TrkB.T1 on TrkB/BDNF signaling (Fig. 5). Specifically, over a 7 month period, $B D N F^{+/-}$; $\operatorname{TrkBT1}^{-/-}$mice gained significantly less weight than $B D N F^{+/-}$ mice. $B D N F^{+/-} ; \operatorname{TrkB} . T 1^{+/-}$mice were not significantly different weight-wise early in life. However, over time, their weight stabilized, achieving a lower final weight than $B D N F^{+/-}$mice (Fig. $5 A)$.

When applying the resident-intruder paradigm, both $\mathrm{BDNF}^{+/-} ; \mathrm{TrkB}_{\mathrm{T}} \mathrm{T}^{+/-}$and $\mathrm{BDNF^{+/- }} ; \mathrm{TrkBT1}^{-/-}$mice showed a significant decrease in aggressive behavior as measured by the latency to first attack and the total number of biting attacks during 5 min exposures to an intruder mouse (Fig. $5 B, C$ ). Importantly, the partial rescue observed in both $B D N F^{+/-} ; \operatorname{TrkB} . T 1^{+/-}$ and $B D N F^{+/-}$;TrkBT1 ${ }^{-/-}$mice suggests that the phenotypic changes are not caused by intrinsic physiological alterations attributable to the complete loss of TrkB.T1 but rather by a reduced dominant-negative effect on TrkB.FL or a decrease in BDNF sequestration, resulting in the potentiation of TrkB.FL signaling.

\section{Discussion}

The physiological role of TrkB.T1 is still unknown. Here we examined the consequences of TrkB.T1 deletion in mouse development as well as the role of the endogenous TrkB.T1 receptor on BDNF signaling in vivo. We found that loss of TrkB.T1 led to increased anxiety-related behavior that is associated with structural alterations in neurites of neurons of the amygdala. Moreover, we show that reducing TrkB.T1 levels in vivo partially rescues the phenotypes caused by loss of one BDNF allele.

Truncated TrkB.T1 receptors were first described almost 20 years ago, but to date very little is known about their physiological role in neurotrophin signaling and development. One of the major obstacles in identifying these functions has been the absence of a suitable animal model lacking only this receptor isoform. Previous animal models have been generated targeting either the full-length isoform or all TrkB isoforms (Klein et al., 1993; Rohrer et al., 1999). TrkB.FL receptor exerts strong prosurvival functions in neurons, and, consequently, its deletion causes extreme phenotypes, which have made it impossible to evaluate any long-term functional roles the truncated TrkB isoform might have. Recently, we targeted the TrkB locus to specifically delete the TrkB.T1 isoform without affecting the level or the spatiotemporal pattern of expression of TrkB.FL (Dorsey et al., 2006). These animals are viable and fertile, and no obvious phenotype has been detected by simple observation. The lack of strong developmental phenotypes in our model supports the idea that the predominant role of TrkB.T1 is not to support neuronal survival. Instead, it might be involved in the regulation of BDNF signaling and in the differentiation and/or function of neurons. Alternatively, it suggests that other truncated TrkB (e.g., TrkB.T2) or TrkC receptors may compensate for TrkB.T1 deficiency. However, we did not find any upregulation of other truncated TrkB or TrkC receptor isoform in either neurons nor glia lacking TrkB.T1. Moreover, truncated TrkC receptors are present at a significantly lower level than TrkB.T1, suggesting that, at least at the expression level, other truncated Trk receptors may not be able to compensate for the loss of the most expressed of all truncated Trk receptors (Dorsey et al., 2006, and data not shown). 
A

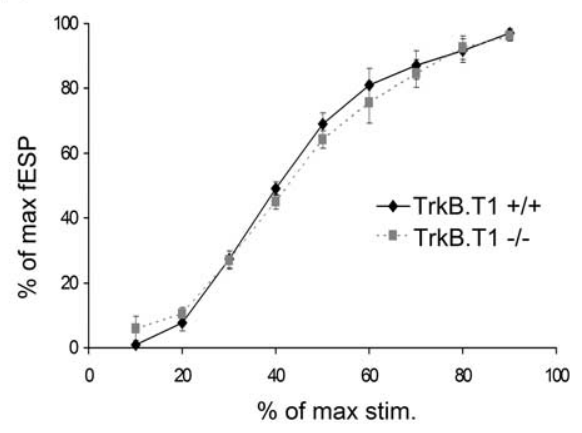

B

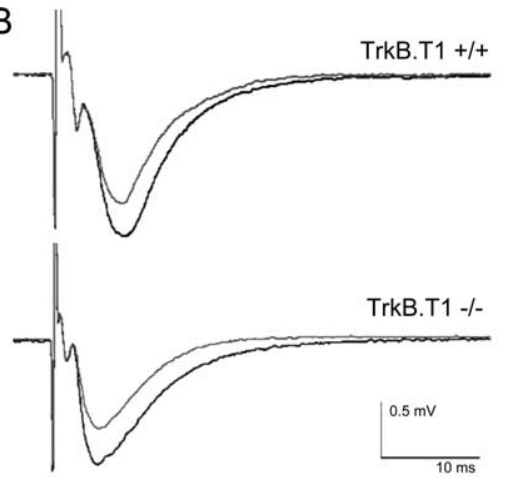

C

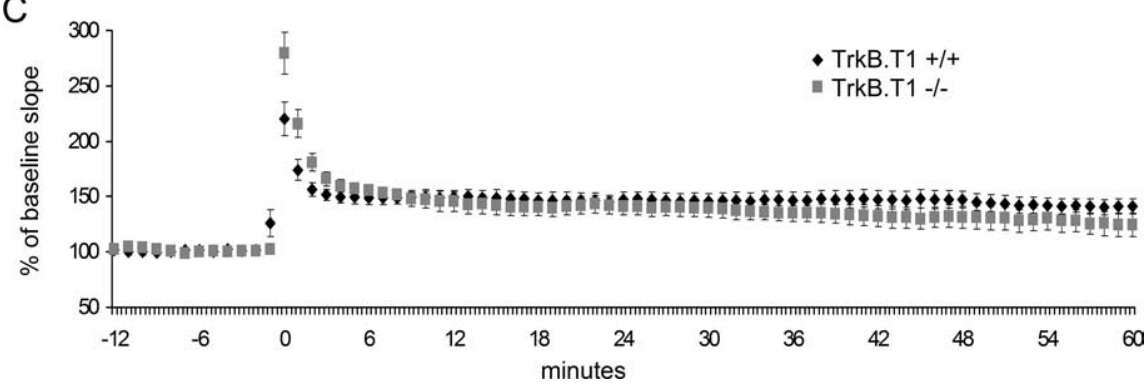

Figure 4. TrkB.T1 does not affect hippocampal basal synaptic transmission and LTP. A, Input- output curve: initial slope of fEPSP s obtained with increased stimulus intensity were plotted versus the response normalized to the maximal response obtained ( $n=5$ per genotype). $\boldsymbol{B}$, fEPSP recorded in wild-type and mutant TrkB.T1 mice. The average of five traces obtained before (gray) and $1 \mathrm{~h}$ after (black) the LTP conditioning protocol (2 times at $250 \mathrm{~ms}, 100 \mathrm{~Hz}$ train) are represented. C, Time course of initial slope of fEPSP before and after LTP induction in wild-type (black diamonds; $n=12$ ) and $T r k B . T 1^{-1-}$ (gray squares; $n=11$ ) mice.

A role for TrkB.T1 in regulating BDNF signaling was first proposed when it was cloned, and such a function has been supported by its pattern of expression and a number of in vitro and in vivo overexpression experiments (Klein et al., 1990; Middlemas et al., 1991; Biffo et al., 1995; Eide et al., 1996; Saarelainen et al., 2000b; Haapasalo et al., 2001). However, whether physiological levels of this receptor isoform could exert such activity has never been definitively proven. Our study, by showing partial rescue of BDNF haploinsufficiency by TrkB.T1 deletion proves that physiologically TrkB.T1 indeed limits BDNF signaling in vivo (Fig. 5). A key question is why would an organism require a negative modulator of BDNF signaling such as TrkB.T1? A number of studies have suggested that excessive BDNF is involved in the pathogenesis of epilepsy, mania, and autism (for review, see Tsai, 2007). Moreover, it has been shown that TrkB.FL is required for epileptogenesis in the kindling model and that zinc, a metal abundantly present in the brain, can transactivate synaptic TrkB by a neuronal activity-regulated mechanism (He et al., 2004; Huang et al., 2008). Thus, although TrkB.FL signaling is important for synaptic plasticity, it appears that excessive activation of this receptor could be one of the causes leading to hyperexcitability of specific brain areas, which in turn could cause epilepsy. The finding that physiological TrkB.T1 limits BDNF signaling in vivo suggests that TrkB.T1 may be part of a mechanism critical in preventing pathological activation of the TrkB.FL. It will be of interest to investigate whether TrkB.T1 may represent an important buffer to prevent overactivation of TrkB.FL during neuronal activity.

Alternatively, the primary function of TrkB.T1 could be the modulation of other cellular functions independent of the TrkB kinase receptor (Baxter et al., 1997; Rose et al., 2003; Ohira et al., 2005). For example, TrkB.T1 has been reported to regulate astro- cytic morphology by directly interacting with Rho GDP dissociation inhibitor 1 and modulate calcium release from intracellular stores in astrocytes (Rose et al., 2003; Ohira et al., 2005). However, the lack of a more dramatic phenotype in this model also indicates that TrkB.T1 does not have a critical widespread function in CNS, as might be suggested by its potential role in astroglia calcium homeostasis (Reichardt, 2003).

TrkB.FL and TrkB.T1 expression are tightly regulated during development. Although TrkB.FL is the highest expressed isoform in early CNS development, TrkB.T1 is dramatically upregulated during postnatal brain development (Allendoerfer et al., 1994; Escandón et al., 1994; Fryer et al., 1996). The reason for this tight regulation of TrkB receptor isoform expression is unknown. In addition to the above-discussed role in the control of TrkB.FL activation, it has been suggested that TrkB.T1 and TrkB.FL can regulate distinct modes of dendritic growth in visual cortical neurons. Specifically, TrkB.FL promotes the addition of short branches in dendritic regions proximal to the cell body, whereas TrkB.T1 induces the extension of dendrites in regions more distal to the soma. These data suggest that expression of the correct set of TrkB isoforms is essential for normal dendritic development (Yacoubian and Lo, 2000). Indeed, we found that TrkB.T1 deficiency does affect neurite complexity, as well as dendrite length of neurons of the amygdala. Although we cannot assess whether this effect is caused by a dominantnegative inhibition of TrkB.FL or by a different mechanism, these data provide definitive evidence that, in certain neuronal populations, physiological TrkB.T1 is important in regulating neuronal branching. This effect is not widespread because, in contrast with the amygdala, our behavioral and structural analysis of the hippocampus has not shown any change so far, suggesting that there are different regional TrkB.T1 requirements during neuronal development.

TrkB.T1 is also present at cortical glutamatergic synapses together with TrkB.FL, suggesting that it may play a role in synaptic plasticity (Gomes et al., 2006). Surprisingly, we have so far failed to detect any clear electrophysiological abnormality in the hippocampus, a region whose neurons express both full-length and TrkB.T1 receptors. Lack of an effect on induction or maintenance of LTP has been reported also in transgenic mice overexpressing TrkB.T1 in the cortex and the hippocampus, suggesting that TrkB.T1 is not limiting for the induction of LTP (Saarelainen et al., 2000a). A previous study had shown LTP inhibition in hippocampal slices overexpressing TrkB.T1 delivered by adenoviral infection, but it has been suggested that different levels of expression at synapses were responsible for the discrepancy (Li et al., 1998; Saarelainen et al., 2000a). Nevertheless, our data strongly indicates that, at least in young animals, endogenous TrkB.T1 is not limiting the induction of LTP.

In conclusion, we have shown that truncated TrkB.T1 receptor is indeed an important regulator of BDNF signaling in vivo, it is involved in the control of complex behaviors, and it affects 

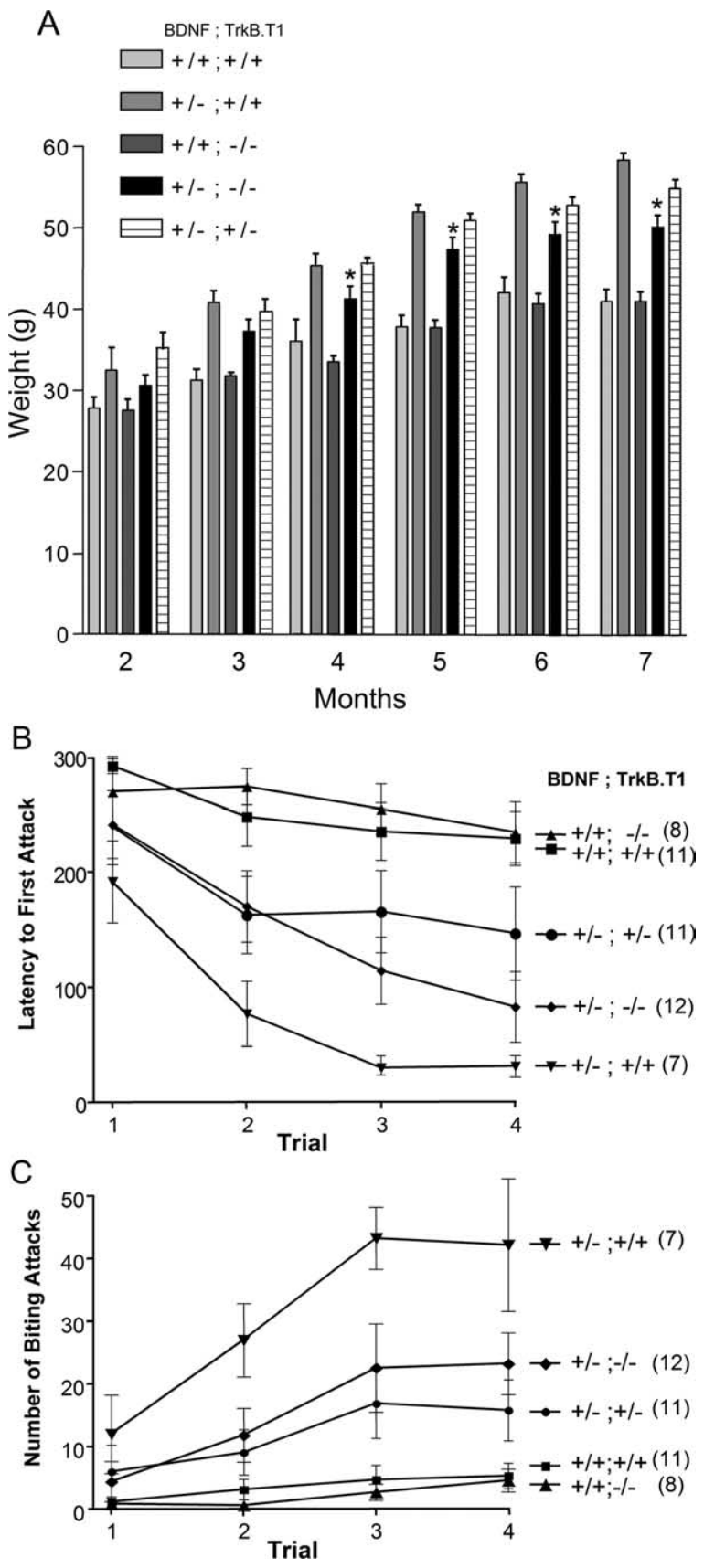

Figure 5. TrkB.T1 deletion partially rescues the obesity and the aggressive phenotype


$\mathrm{BDNF}^{+/-}, \mathrm{TrkB}_{\mathrm{N} 1^{+/-}} ; \mathrm{BDNF}^{+/-}$, and $\mathrm{BDNF}^{+/-}$mice. Mice had ad libitum access to food and water. The weight of the indicated mouse groups was monitored once a month until mice reached an age of 7 months. Bars indicate means \pm SEM. Each group comprised a minimum of eight mice. At 4 months of age, one-way ANOVA statistical analysis followed by Tukey's multiple comparison test shows that the weight of $B D N F^{+/-} ; T_{K k B .} T 1^{-/-}$is significantly different from that of $B D N F^{+/-}\left({ }^{*} p<0.05\right)$ mice but not from that of wild-type animals. At 5, 6, and 7 months, the weights of $B D N F^{+/-} ; T_{r k B . T 1^{-/-}}$are significantly different from both wild-type and $B D N F^{+/-}$mice $\left({ }^{*} p<0.05\right) . B, C$, Aggressive behavior was assessed for each of the aboveindicated genotype using the resident/intruder paradigm. The latency to first attack $(\boldsymbol{B})$ was measured on 4 consecutive days ( 1 session of 5 min a day) for each genotype using an age- and weight-matched wild-type intruder mouse. The number of mice for each group is indicated in parentheses. Means \pm SEM bars are indicated. Latency to first attack in trial 3 as analyzed by one-way ANOVA and Tukey's multiple comparison test reveals a significant difference between $\mathrm{BDNF}^{+/-}$and $\mathrm{BDNF}^{+/-} ; \mathrm{TrkB}_{\mathrm{T}} \mathrm{T}^{+/-}(p<0.05)$ but not between $\mathrm{BDNF}^{+/+} ; \mathrm{TrkB}_{\mathrm{T}} \mathrm{T}^{+/+}$ and $B D N F^{+/-} ; \mathrm{TrkB}_{\mathrm{N}} \mathrm{T}^{+/-}$. C, Number of biting attacks over a period of $5 \mathrm{~min}$. The number of biting attacks by $B D N F^{+/-}$mice in trials $2-4$ is significantly different $(p<0.05)$ from that of $\mathrm{BDNF}^{+/-} ; \mathrm{TrKB}_{\mathrm{N}} \mathrm{1}^{+/-}$but not of $\mathrm{BDNF}^{+/-} ; \mathrm{TrkB}_{\mathrm{T}} \mathrm{T1^{-/- }}$ mice. neurite complexity in the amygdala. Additional analysis of aged animals and the use of paradigms to challenge these mutants will help to shed additional light into other physiological roles of TrkB.T1, the highest expressed TrkB isoform in the mature mammalian brain.

\section{References}

Allendoerfer KL, Cabelli RJ, Escandón E, Kaplan DR, Nikolics K, Shatz CJ (1994) Regulation of neurotrophin receptors during the maturation of the mammalian visual system. J Neurosci 14:1795-1811.

Baxter GT, Radeke MJ, Kuo RC, Makrides V, Hinkle B, Hoang R, MedinaSelby A, Coit D, Valenzuela P, Feinstein SC (1997) Signal transduction mediated by the truncated trkB receptor isoforms, trkB.T1 and trkB.T2. J Neurosci 17:2683-2690.

Bibel M, Barde YA (2000) Neurotrophins: key regulators of cell fate and cell shape in the vertebrate nervous system. Genes Dev 14:2919-2937.

Biffo S, Offenhäuser N, Carter BD, Barde YA (1995) Selective binding and internalisation by truncated receptors restrict the availability of BDNF during development. Development 121:2461-2470.

Bothwell M (1995) Functional interactions of neurotrophins and neurotrophin receptors. Annu Rev Neurosci 18:223-253.

Cellerino A, Maffei L (1996) The action of neurotrophins in the development and plasticity of the visual cortex. Prog Neurobiol 49:53-71.

Chao MV, Hempstead BL (1995) p75 and Trk: a two-receptor system. Trends Neurosci 18:321-326.

Chao MV, Rajagopal R, Lee FS (2006) Neurotrophin signalling in health and disease. Clin Sci 110:167-173.

Chen ZY, Jing D, Bath KG, Ieraci A, Khan T, Siao CJ, Herrera DG, Toth M, Yang C, McEwen BS, Hempstead BL, Lee FS (2006) Genetic variant BDNF (Val66Met) polymorphism alters anxiety-related behavior. Science 314:140-143.

Coppola V, Tessarollo L (2004) Control of hyperphagia prevents obesity in BDNF heterozygous mice. Neuroreport 15:2665-2668.

Dorsey SG, Renn CL, Carim-Todd L, Barrick CA, Bambrick L, Krueger BK, Ward CW, Tessarollo L (2006) In vivo restoration of physiological levels of truncated TrkB.T1 receptor rescues neuronal cell death in a trisomic mouse model. Neuron 51:21-28.

Egan MF, Kojima M, Callicott JH, Goldberg TE, Kolachana BS, Bertolino A, Zaitsev E, Gold B, Goldman D, Dean M, Lu B, Weinberger DR (2003) The BDNF val66met polymorphism affects activity-dependent secretion of BDNF and human memory and hippocampal function. Cell 112:257-269.

Eide FF, Vining ER, Eide BL, Zang K, Wang XY, Reichardt LF (1996) Naturally occurring truncated trkB receptors have dominant inhibitory effects on brain-derived neurotrophic factor signaling. J Neurosci 16:3123-3129.

Escandón E, Soppet D, Rosenthal A, Mendoza-Ramírez JL, Szönyi E, Burton LE, Henderson CE, Parada LF, Nikolics K (1994) Regulation of neurotrophin receptor expression during embryonic and postnatal development. J Neurosci 14:2054-2068.

Esteban PF, Yoon HY, Becker J, Dorsey SG, Caprari P, Palko ME, Coppola V, Saragovi HU, Randazzo PA, Tessarollo L (2006) A kinase-deficient TrkC receptor isoform activates Arf6-Racl signaling through the scaffold protein tamalin. J Cell Biol 173:291-299.

Friedman WJ, Greene LA (1999) Neurotrophin signaling via Trks and p75. Exp Cell Res 253:131-142.

Fryer RH, Kaplan DR, Feinstein SC, Radeke MJ, Grayson DR, Kromer LF (1996) Developmental and mature expression of full-length and truncated TrkB receptors in the rat forebrain. J Comp Neurol 374:21-40.

Garner AS, Large TH (1994) Isoforms of the avian TrkC receptor: a novel kinase insertion dissociates transformation and process outgrowth from survival. Neuron 13:457-472.

Gomes RA, Hampton C, El-Sabeawy F, Sabo SL, McAllister AK (2006) The dynamic distribution of TrkB receptors before, during, and after synapse formation between cortical neurons. J Neurosci 26:11487-11500.

Haapasalo A, Koponen E, Hoppe E, Wong G, Castrén E (2001) Truncated trkB.T1 is dominant negative inhibitor of trkB.TK ${ }^{+}$-mediated cell survival. Biochem Biophys Res Commun 280:1352-1358.

Hariri AR, Goldberg TE, Mattay VS, Kolachana BS, Callicott JH, Egan MF, Weinberger DR (2003) Brain-derived neurotrophic factor val66met polymorphism affects human memory-related hippocampal activity and predicts memory performance. J Neurosci 23:6690-6694.

He XP, Kotloski R, Nef S, Luikart BW, Parada LF, McNamara JO (2004) 
Conditional deletion of TrkB but not BDNF prevents epileptogenesis in the kindling model. Neuron 43:31-42.

Hempstead BL (2002) The many faces of p75NTR. Curr Opin Neurobiol 12:260-267.

Huang EJ, Reichardt LF (2001) Neurotrophins: roles in neuronal development and function. Annu Rev Neurosci 24:677-736.

Huang YZ, Pan E, Xiong ZQ, McNamara JO (2008) Zinc-mediated transactivation of TrkB potentiates the hippocampal mossy fiber-CA3 pyramid synapse. Neuron 57:546-558.

Kaplan DR, Miller FD (2000) Neurotrophin signal transduction in the nervous system. Curr Opin Neurobiol 10:381-391.

Kernie SG, Liebl DJ, Parada LF (2000) BDNF regulates eating behavior and locomotor activity in mice. EMBO J 19:1290-1300.

Klein R, Conway D, Parada LF, Barbacid M (1990) The trkB tyrosine protein kinase gene codes for a second neurogenic receptor that lacks the catalytic kinase domain. Cell 61:647-656.

Klein R, Smeyne RJ, Wurst W, Long LK, Auerbach BA, Joyner AL, Barbacid M (1993) Targeted disruption of the trkB neurotrophin receptor gene results in nervous system lesions and neonatal death. Cell 75:113-122.

Li YX, Xu Y, Ju D, Lester HA, Davidson N, Schuman EM (1998) Expression of a dominant negative TrkB receptor, T1, reveals a requirement for presynaptic signaling in BDNF-induced synaptic potentiation in cultured hippocampal neurons. Proc Natl Acad Sci U S A 95:10884-10889.

Lu B, Pang PT, Woo NH (2005) The yin and yang of neurotrophin action. Nat Rev Neurosci 6:603-614.

Lyons WE, Mamounas LA, Ricaurte GA, Coppola V, Reid SW, Bora SH, Wihler C, Koliatsos VE, Tessarollo L (1999) Brain-derived neurotrophic factor-deficient mice develop aggressiveness and hyperphagia in conjunction with brain serotonergic abnormalities. Proc Natl Acad Sci U S A 96:15239-15244.

McAllister AK, Katz LC, Lo DC (1999) Neurotrophins and synaptic plasticity. Annu Rev Neurosci 22:295-318.

Middlemas DS, Lindberg RA, Hunter T (1991) trkB, a neural receptor protein-tyrosine kinase: evidence for a full-length and two truncated receptors. Mol Cell Biol 11:143-153.

Mitra R, Jadhav S, McEwen BS, Vyas A, Chattarji S (2005) Stress duration modulates the spatiotemporal patterns of spine formation in the basolateral amygdala. Proc Natl Acad Sci U S A 102:9371-9376.

Nykjaer A, Lee R, Teng KK, Jansen P, Madsen P, Nielsen MS, Jacobsen C, Kliemannel M, Schwarz E, Willnow TE, Hempstead BL, Petersen CM (2004) Sortilin is essential for proNGF-induced neuronal cell death. Nature 427:843-848.

Ohira K, Kumanogoh H, Sahara Y, Homma KJ, Hirai H, Nakamura S, Hayashi M (2005) A truncated tropomyosin-related kinase B receptor, T1, regulates glial cell morphology via Rho GDP dissociation inhibitor 1. J Neurosci 25:1343-1353.

Palko ME, Coppola V, Tessarollo L (1999) Evidence for a role of truncated trkC receptor isoforms in mouse development. J Neurosci 19:775-782.
Reichardt LF (2003) Neurobiology: signals that make waves. Nature 426:25-26.

Rios M, Fan G, Fekete C, Kelly J, Bates B, Kuehn R, Lechan RM, Jaenisch R (2001) Conditional deletion of brain-derived neurotrophic factor in the postnatal brain leads to obesity and hyperactivity. Mol Endocrinol 15:1748-1757.

Rohrer B, Korenbrot JI, LaVail MM, Reichardt LF, Xu B (1999) Role of neurotrophin receptor TrkB in the maturation of rod photoreceptors and establishment of synaptic transmission to the inner retina. J Neurosci 19:8919-8930.

Rose CR, Blum R, Pichler B, Lepier A, Kafitz KW, Konnerth A (2003) Truncated TrkB-T1 mediates neurotrophin-evoked calcium signalling in glia cells. Nature 426:74-78.

Saarelainen T, Pussinen R, Koponen E, Alhonen L, Wong G, Sirviö J, Castrén E (2000a) Transgenic mice overexpressing truncated trkB neurotrophin receptors in neurons have impaired long-term spatial memory but normal hippocampal LTP. Synapse 38:102-104.

Saarelainen T, Lukkarinen JA, Koponen S, Gröhn OH, Jolkkonen J, Koponen E, Haapasalo A, Alhonen L, Wong G, Koistinaho J, Kauppinen RA, Castrén E (2000b) Transgenic mice overexpressing truncated trkB neurotrophin receptors in neurons show increased susceptibility to cortical injury after focal cerebral ischemia. Mol Cell Neurosci 16:87-96.

Snider WD (1994) Functions of the neurotrophins during nervous system development: what the knockouts are teaching us. Cell 77:627-638.

Tessarollo L (1998) Pleiotropic functions of neurotrophins in development. Cytokine Growth Factor Rev 9:125-137.

Tsai SJ (2007) Increased central brain-derived neurotrophic factor activity could be a risk factor for substance abuse: implications for treatment. Med Hypotheses 68:410-414.

Tsoulfas P, Soppet D, Escandon E, Tessarollo L, Mendoza-Ramirez JL, Rosenthal A, Nikolics K, Parada LF (1993) The rat trkC locus encodes multiple neurogenic receptors that exhibit differential response to neurotrophin-3 in PC12 cells. Neuron 10:975-990.

Valenzuela DM, Maisonpierre PC, Glass DJ, Rojas E, Nuñez L, Kong Y, Gies DR, Stitt TN, Ip NY, Yancopoulos GD (1993) Alternative forms of rat TrkC with different functional capabilities. Neuron 10:963-974.

Vyas A, Mitra R, Shankaranarayana Rao BS, Chattarji S (2002) Chronic stress induces contrasting patterns of dendritic remodeling in hippocampal and amygdaloid neurons. J Neurosci 22:6810-6818.

Vyas A, Pillai AG, Chattarji S (2004) Recovery after chronic stress fails to reverse amygdaloid neuronal hypertrophy and enhanced anxiety-like behavior. Neuroscience 128:667-673.

Xu B, Goulding EH, Zang K, Cepoi D, Cone RD, Jones KR, Tecott LH, Reichardt LF (2003) Brain-derived neurotrophic factor regulates energy balance downstream of melanocortin-4 receptor. Nat Neurosci 6:736-742.

Yacoubian TA, Lo DC (2000) Truncated and full-length TrkB receptors regulate distinct modes of dendritic growth. Nat Neurosci 3:342-349. 